\title{
Ptosis caused by pachydermoperiostosis
}

\author{
J N P Kirkpatrick, P H McKee, D J Spalton
}

\begin{abstract}
Pachydermoperiostosis is a rare inherited disorder which presents with finger clubbing, facial enlargement, and periostitis. $A$ case is described in which surgery for ptosis was performed and the differential diagnosis of the condition is discussed. The histological and ultrastructural appearances of the eyelids show sebaceous gland hyperplasia and excessive deposition of mucin in the dermis and would suggest that pachydermoperiostosis may be an example of a cutaneous mucinosis.
\end{abstract}

Pachydermoperiostosis (Touraine-Solente-Gole syndrome) is a rare inherited syndrome of unknown aetiology in which hypertrophic changes in skin and bone simulate acromegaly. The condition was first described in two brothers by Friedrich in 1868, when it was considered to be an example of acromegaly. ${ }^{1}$ In 1935 Touraine, Solente, and Gole postulated that pachydermoperiostosis was a separate conditon quite distinct from acromegaly or the syndrome of hypertrophic pulmonary osteoarthropathy. ${ }^{2}$

The mode of inheritance of the disease is unclear, but an autosomal dominant pattern with varying expressivity has been suggested. ${ }^{3}$ It is commoner in males, with only a few reported female cases, in whom features of the disease are less marked. The condition presents at puberty, with progression of features into early adult life, after which there is little change. Soft tissue hyperplasia in hands and feet with marked clubbing at the digits occurs. The skin of the face and forehead is thickened and folded, and sebaceous hyperplasia is present. In addition, there may be extensive sagittal folding of the scalp, a condition known as cutis verticis gyrata.

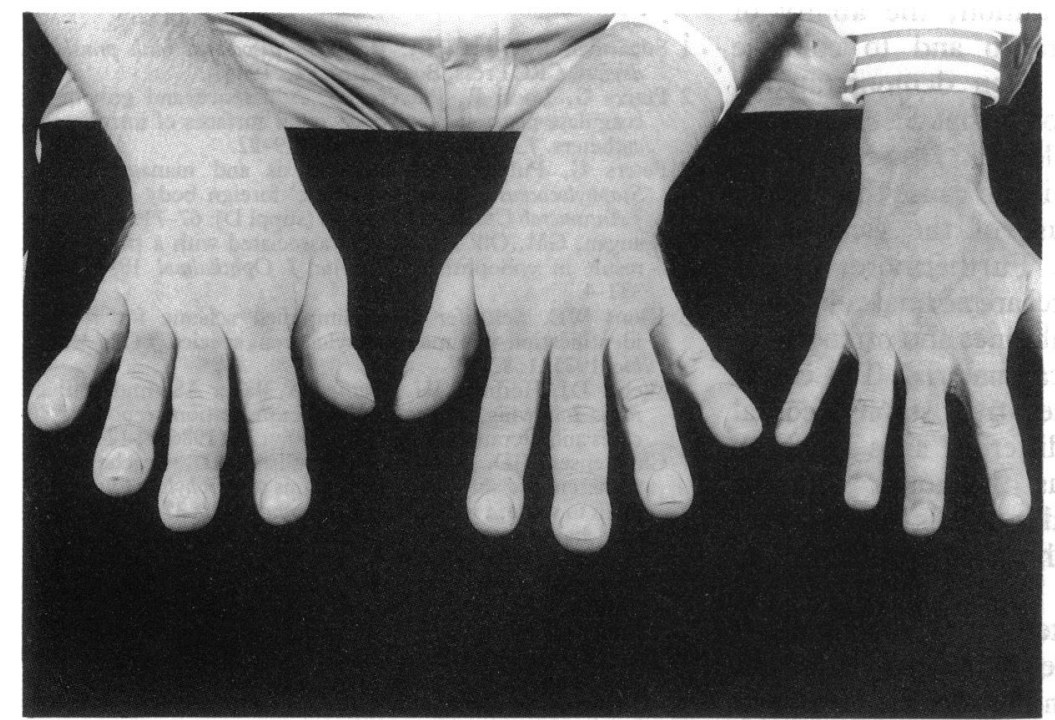

Figure 1 Clubbing and enlargement of hands in pachydermoperiostosis compared with a normal adult hand.
Bones show a periostitis and periosteal new bone formation, with resultant increase in circumference without a reduction in bony strength. Patients may complain of sweating due to hyperhidrosis of hands and feet, but pain is not a feature of this condition in contrast to hypertrophic pulmonary osteoarthropathy.

We report on a patient with this condition who presented with ptosis, and the histopathological features in the eye lids are discussed.

\section{Case report}

A 24-year-old male complained of difficulty in opening both eyes and the presence of crusts on the eyelid margins, particularly in the mornings. Pachydermoperiostosis had been diagnosed at puberty. His brother was also affected.

On examination the typical features of gross clubbing, 'watchglass' fingernails, and enlargement of the hands (Fig 1) and feet were noted. There was marked thickening of the skin of the face and forehead, which appeared furrowed and oily (Fig 2). There were no signs of prognathism or macroglossia. Visual acuity was correctable $6 / 5$ in both eyes; colour vision, pupillary responses, ocular movements, and intraocular examination were normal. Examination of the eyelids showed that the palpebral apertures were reduced to $5 \mathrm{~mm}$ bilaterally, with an S-shaped curve of the upper lid margins (Fig 3A). With the lids closed there was so much redundancy that the upper lids tended to override the lower lids. The skin of the eyelids was thickened, and the tarsal conjunctiva showed a marked papillary response (Fig 3B). The tarsal plates appeared lax, with a vertical height of $14 \mathrm{~mm}$ bilaterally. There was good levator function.

Initially surgery was performed on the right upper lid. A $4 \mathrm{~mm}$ tarsectomy of the tarsal plate was performed via a conjunctival approach, and the lid was shortened by wedge excision. A similar procedure was performed on the left upper lid a few weeks later. The patient made an uncomplicated recovery and had an excellent cosmetic result. Tissue from both eye lids was submitted for histological examination and electron microscopy.

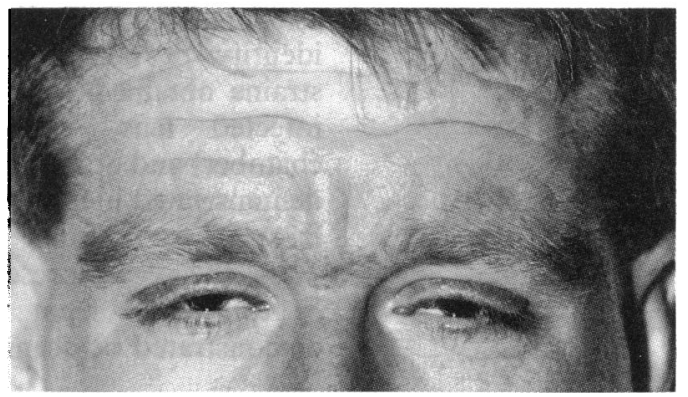

Figure 2 Furrowing of forehead and bilateral ptosis. 


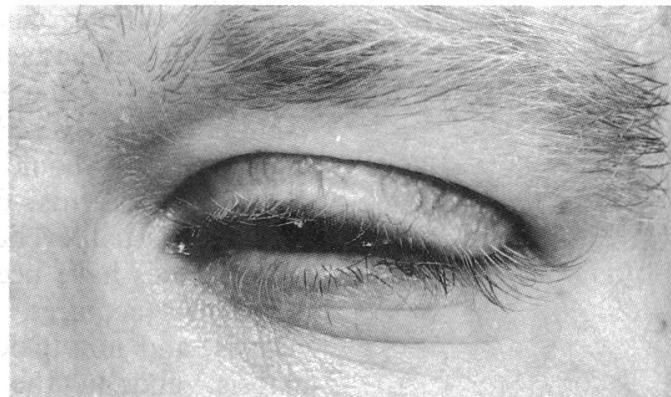

Figure $3 A$ Ptosis and lid thickening of the left eye: note the $S$-shaped curve of the upper lid margin.

\section{Materials and methods}

The specimens were fixed in $10 \%$ formaldehyde and paraffin embedded. Sections $4 \mu \mathrm{m}$ thick were stained with haematoxylin and eosin, periodic acid Schiff with and without diastase predigestion, alcian blue at $\mathrm{pH} 0.5,1.0$, and 2.5 with and without hyaluronidase pretreatment, elastic van Gieson, Masson's trichrome, toluidine blue, and chloracetate esterase.

Fresh tissue was diced into approximately $1 \cdot 0$ $\mathrm{mm}$ cubes and fixed in $2 \%$ glutaraldehyde. They were post-fixed in $1 \%$ osmium tetroxide, dehydrated, and embedded in Araldite. Following examination of a $1.0 \mu \mathrm{m}$, toluidine blue stained 'semi-thin', section, sections from selected regions were cut $80 \mathrm{~nm}$ thick with an LKB ultramicrotome and stained with lead citrate and uranyl acetate. They were examined in a Philips 201 electron microscope at $60 \mathrm{kV}$.

\section{Results}

Both eyelids showed similar features. Most conspicuous was the presence of sebaceous gland hyperplasia. Focal accumulations of mucin, situated predominantly around blood vessels and

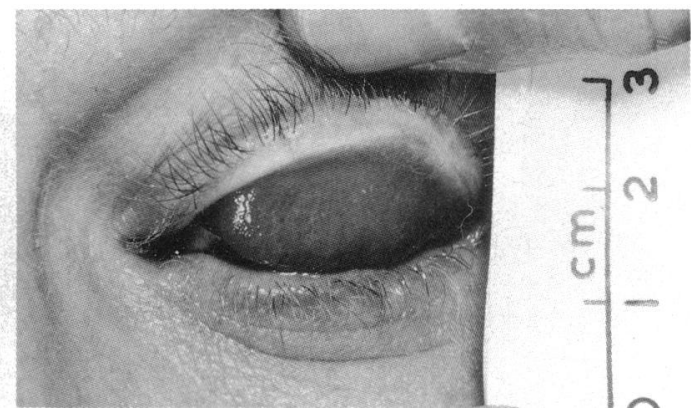

Figure $3 B$ On eversion there is papillary hyperplasia of the tarsal conjunctiva. The vertical dimension measures $14 \mathrm{~mm}$.

adnexae, were also present in the dermis (Fig 4). In places they were associated with stellate fibroblasts (Fig 5). The mucin was focally periodic acid Schiff positive and stained with alcian blue at $\mathrm{pH} 2 \cdot 5$. This was completely abolished by pretreatment with testicular hyaluronidase, confirming that the mucin was composed of hyaluronic acid. Patchy fibrous scarring was present in addition to a heavy chronic inflammatory cell infiltrate consisting of lymphocytes and plasma cells adjacent to the palpebral conjunctiva. Very large numbers of mast cells were widely distributed throughout the eyelids (Fig 6). The tarsal plate histology appeared normal.

Ultrastructurally the sebaceous glands and apocrine glands appeared normal. No morphological abnormality of the fibrous connective tissue components was seen. The only consistent lesion was marked reduplication of the basal lamina surrounding the dermal blood vessels (Fig 7).

\section{Discussion}

Perhaps the most important differential diagnosis

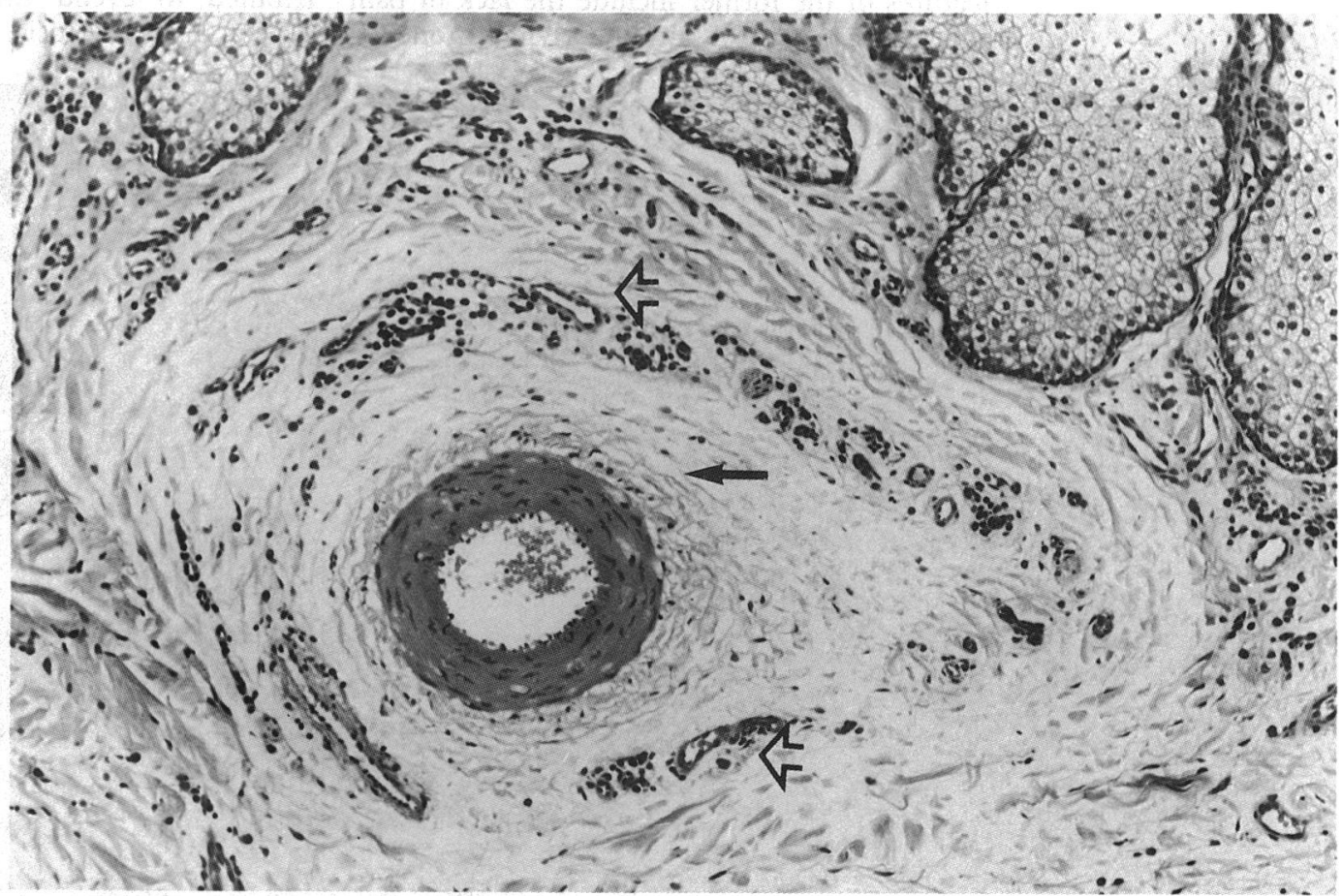

Figure 4 Perivascular mucin deposition has resulted in pallor and wide separation of the adventitial and adjacent collagen fibres round an arterial vessel (black arrow). Chronic inflammatory cell infiltrate surrounds the peripherally located small blood vessels (open arrows). (Haematoxylin and eosin, $\times 1115$.) 


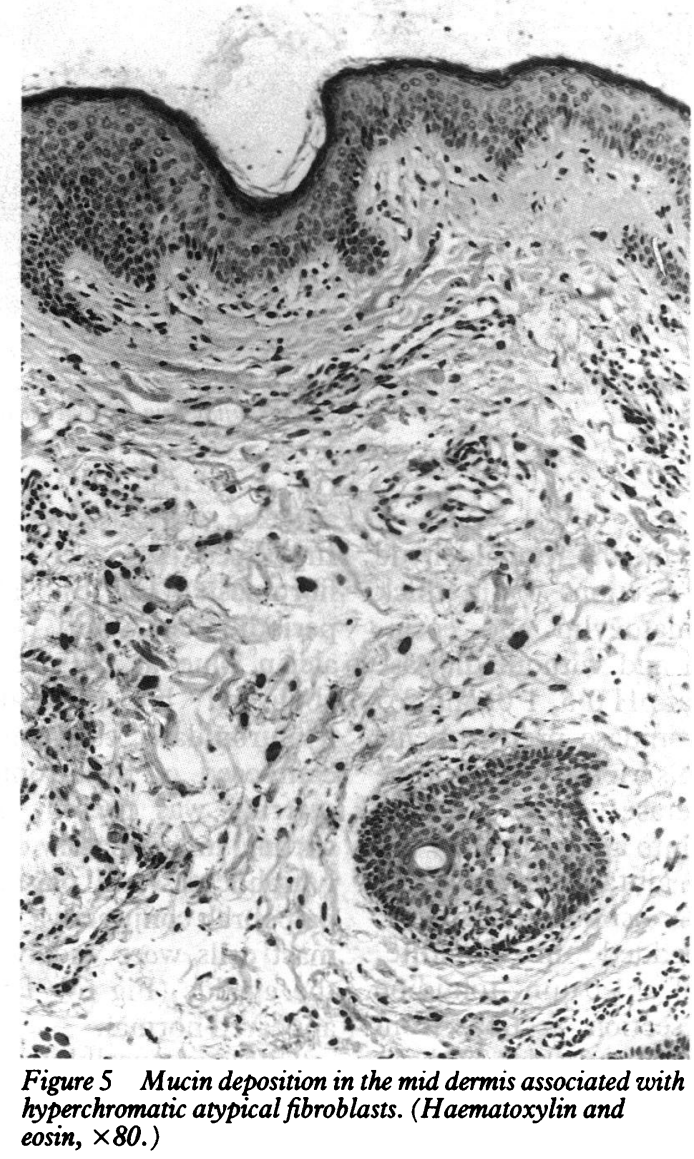

of pachydermoperiostosis is acromegaly, which is differentiated by the typical bony changes as well as increase of serum growth hormone levels. A number of other rare conditions can produce similar appearances. Pachydermoperiostosis may be clinically identical to hypertrophic pulmonary osteoarthropathy, but distinguishing features of the former include the lack of pain and the absence of an underlying bronchial lesion (usually carcinoma). ${ }^{4}$ Abnormal facies such as the leonine facies of leprosy, congenital syphilis, and myxoedema may enter the differential diagnosis. Radiological features of affected digits should be differentiated from rheumatoid arthritis, Paget's disease, and periostitis. Unusual eyelid thickening and facial abnormalities have been described in Ascher's syndrome (acquired double lip, blepharochalasis, and non-toxic goitre ${ }^{5}$, in neurofibromatosis, and in the syndrome of multiple endocrine neoplasia type II $B$, in which lid thickening is caused by neuroma formation in the dermis and conjunctiva of the eyelids. ${ }^{6}$

Ocular features in pachydermoperiostosis are mainly related to ptosis and chronic tarsitis. Ptosis is often not severe, and there are few reported cases in which surgery has been required. Davidson and Smith' described excision of an ellipse of the upper lid with some success, and more recently Ohtsuka and Takayangi ${ }^{8}$ described a three-stage procedure of lid shortening, upper lid tarsectomy, and blepharoplasty. In our case lid shortening and tarsectomy were performed at one sitting with no evidence of delayed or abnormal healing, as was postulated by Ohtsuka and Takayanigi. ${ }^{8}$ Other reported ocular associations with pachydermoperiostosis include corneal leucoma, cataract formation, ${ }^{7}$ and presenile macular dystrophy. ${ }^{10}$

The findings on light microscopy of the eyelids in this case are in accordance with those described previously, ${ }^{71}$ and the cutaneous features are similar to those found elsewhere in the skin. These include sebaceous gland hyperplasia, enlargement of sweat glands, thickening of the dermis with an increase in collagen content, deposition of mucin, and perivascular lymphocytic infiltration. ${ }^{1213}$ In our case sebaceous hyperplasia and dermal mucin deposition were the most prominent of those features and contributed to eyelid thickening and thus the development of ptosis. This contrasts with the

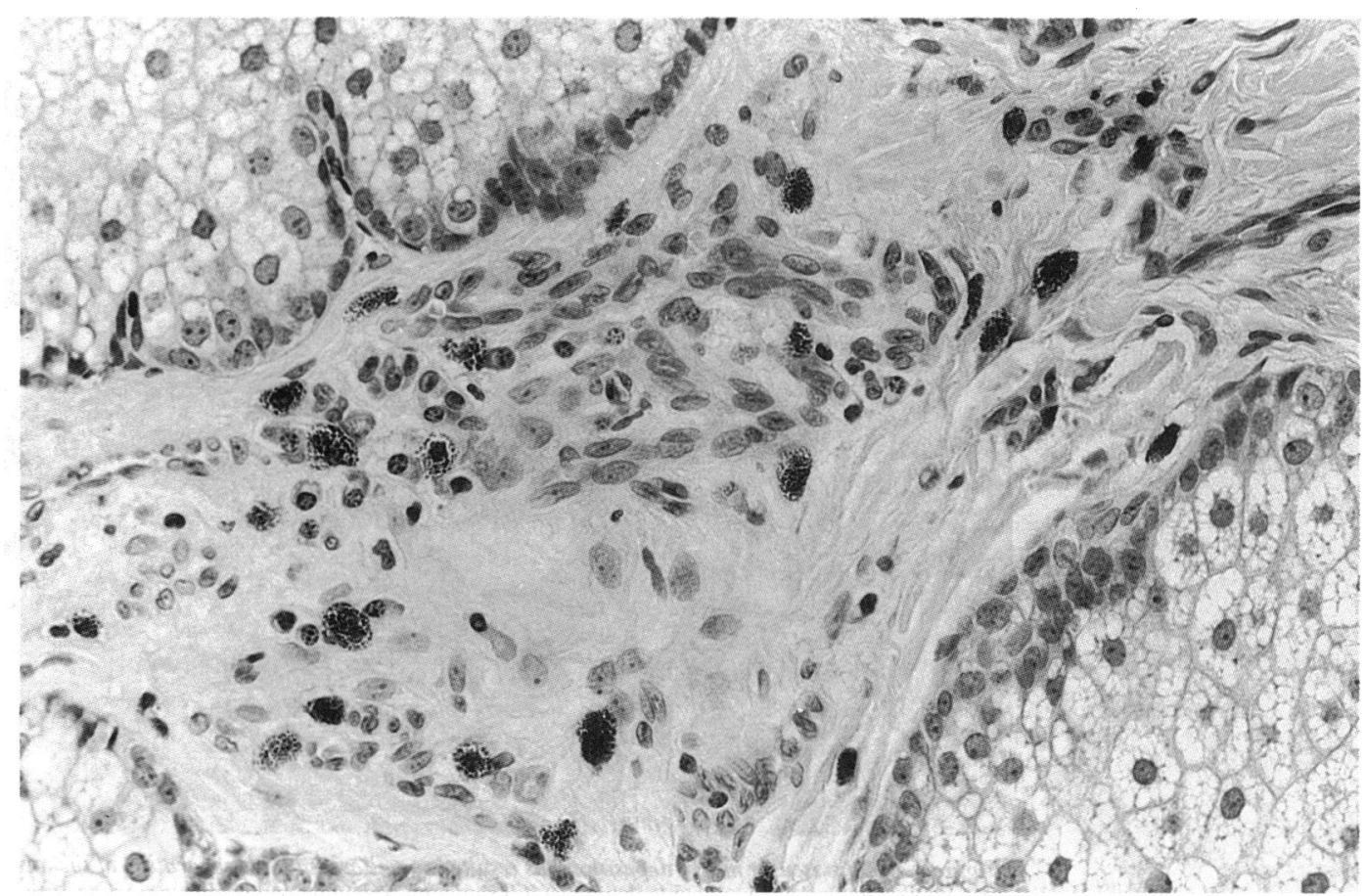

Figure 6 Granulated mast cells are conspicuous in the dermis. (Haematoxylin and eosin, $\times 570$.) 


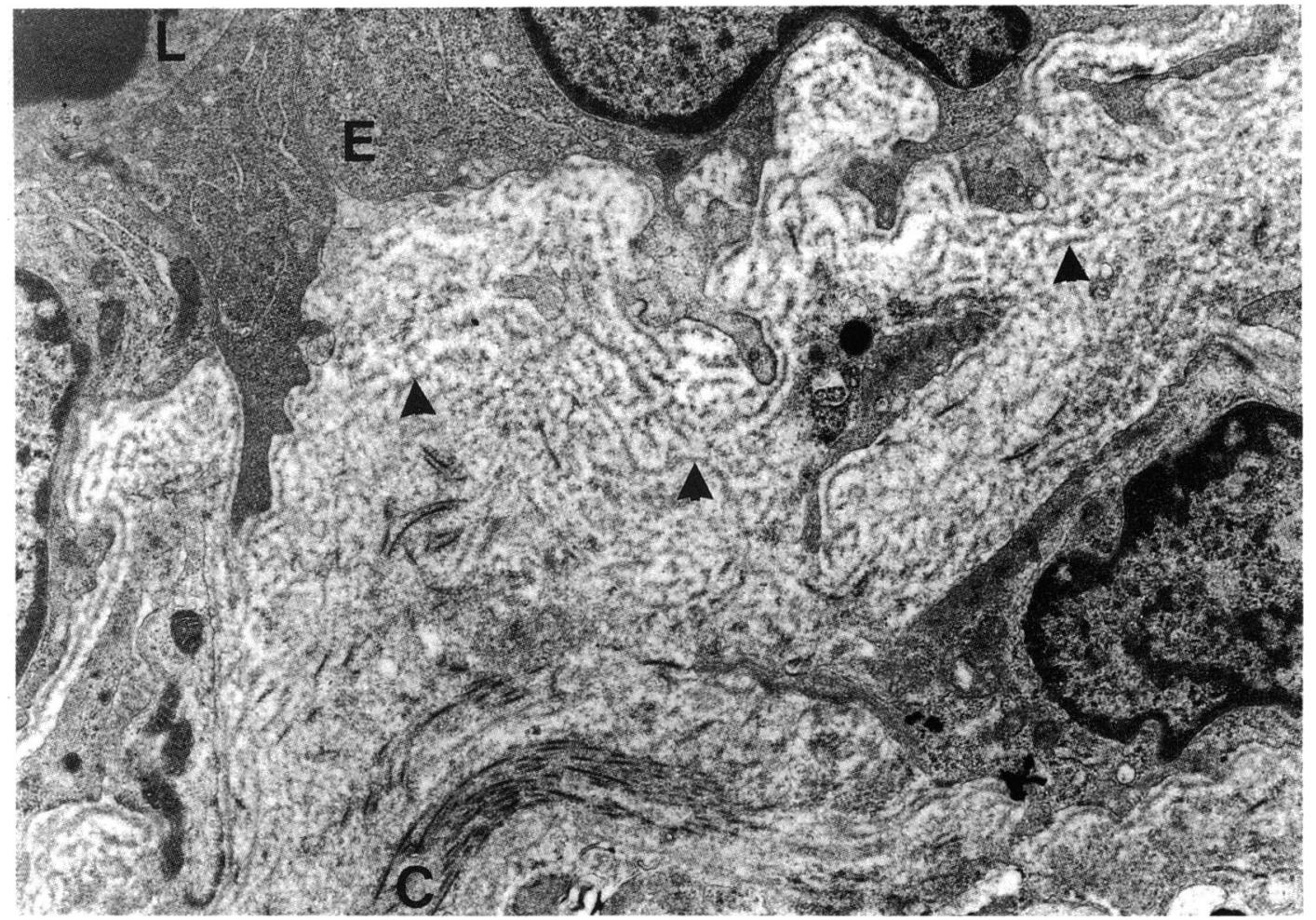

Figure 7 Electronmicrograph showing extensive reduplication of the basal lamina (arrowheads) of a dermal venule. ( $\times 12$ 320.) $L=$ lumen. $E=$ endothelial cell. $C=$ collagen.

marked tarsal plate scarring reported by Downes et al, "1 who postulated that the basic abnormality was a hyperplasia of the sebaceous and meibomian glands with secondary inflammatory changes of the tarsal plate. The conjunctival appearance of macroscopic papillary response and a microscopic chronic inflammatory infiltrate with increase in goblet cell numbers has been described $^{56}$; it may be a non-specific feature of reduced lid mobility exacerbated by the tendency for the lax upper lids to override the lower lid and abrade the lashes. The ultrastructural findings in the eyelids of patients with pachydermoperiostosis have not been previously reported. There appear to be no specific features indicative of the disease. The finding of basal lamina reduplication round the dermal blood vessels has also been described in the skin from other sites in pachydermoperiostosis. ${ }^{13}$ It is, however, a completely non-specific feature which has been described in a wide variety of conditions such as telangiectasia, lipid proteinosis, diabetes, and porphyria. ${ }^{14}$

We believe that the deposition of dermal mucin seen in this case and reported elsewhere, together with the inherited nature of the disease, suggests that pachydermoperiostosis could be classified among the group of primary cutaneous mucinoses. This group of connective tissue disorders shows deposition of fibroblast derived mucin in the dermis, which may be focal or diffuse and is often associated with other systemic abnormalities. These diseases show a common mucin deposition which is a glycosaminoglycan consisting of hyaluronic acid bound to small amounts of chondroitin sulphate and heparin. This is in contrast to the storage diseases, Hunter's and Hurler's syndromes, where the predominant mucin is chondroitin sulphate alone. Examples of the primary cutaneous mucinoses include myxoedema, pretibial myxoedema, and lichen myxoedematosus, in which the common histopathological features include mucin deposition in the dermis together with variable numbers of stellate fibroblasts and a perivascular chronic inflammatory cell infiltrate. ${ }^{15}$ The mucin characteristics and the histology in pachydermoperiostosis appear to be similar. To clarify the situation further it might be of benefit to perform fibroblast culture studies and more precise glycosaminoglycan analyses.

1 Friedrich N. Hyperostose des gesammten skelettes. Virchows $\operatorname{Arch}(A)$ 1868; 43: 83-7.

2 Touraine A, Solente G, Gole L. Un syndrome ostéodermopathique: la pachydermie plicaturée avec pachyperiostose des extrémités. Presse Med 1935; 43: 1820-4.

3 Rimoin DL. Pachydermoperiostosis (idiopathic clubbing and periostosis). $N$ Engl f Med 1965; 272: 923-31.

4 Vogl A, Goldfischer S. Pachydermoperiostosis: primary or idiopathic hypertrophic osteoarthropathy. Am f Med 1962 33: $166-87$.

5 Barnett ML, Bosshardt LL, Morgan AF. Double lip with blepharochalasis (Ascher's syndrome). Oral Surg 1972; 34: 727-33.

6 Schimke RN, Hartmann WH, Prout TE, Rimoin DL. Syndrome of bilateral phaeochromocytoma, medullary thyroid carcinoma and multiple neuromas. $N$ Engl $\mathcal{F}$ Med 1968; 279: 1-7. 
7 Davidson SI, Smith JL. Pachydermoperiostosis: a rare cause of ptosis. Trans Ophthalmol Soc UK 1970; 90: 539-50.

8 Ohtsuka M, Takayanagi S. Ptosis caused by pachydermoperiostosis. Plast Reconstr Surg 1988; 81: 88-90.

9 Joseph B, Chacko V. Acro-osteolysis associated with hypertrophic pulmonary osteoarthropathy and pachydermoperiostosis. Radiology 1985; 154: 343-4.

10 Duke-Elder S. The ocular adnexa. System of Ophthalmology. London: Kimpton, 1974; 13 (1): 356-61.

11 Downes RN, Mininni F, Collin JRO, Harrad RA, Graham CM. Floppy eyelid syndrome in pachydermoperiostosis. Orbit 1989; 8: 93-9.
12 Hambrick GW, Carter DM. Pachydermoperiostosis. Arch Dermatol 1966; 94: 594-608.

13 Matucci-Cerinic M, Cinti S, Morroni M, et al. Pachydermoperiostosis (primary hypertrophic osteoarthropathy): report of a case with evidence of endothelial and corrective tissue involvement. Ann Rheum Dis 1989; 48: 240-6.

14 Shelley WB, Shelley ED, Burmeister V. The laminate capillary and its wall of multiple basement membranes. $\mathrm{Br} \mathcal{F}$ Dermatol 1988; 118: 327-31.

15 Truhan AP, Roenigk HH. The cutaneous mucinoses. $7 \mathrm{Am}$ Acad Dermatol 1986; 14: 1-18. 